\title{
Endovascular Management of latrogenic Vascular Injury in the Craniocervical Region
}

\author{
Elcin AYDIN ${ }^{1}$, Mustafa GOK${ }^{2}$, Asim ESENKAYA ${ }^{3}$, Celal CINAR ${ }^{4}$, Ismail ORAN ${ }^{4}$ \\ 'Başkent University, Department of Radiology, Izmir, Turkey \\ ${ }^{2}$ Adnan Menderes University, Department of Radiology, Aydın, Turkey \\ ${ }^{3}$ Trakya University, Department of Radiology, Edirne, Turkey \\ ${ }^{4}$ Ege University, Department of Radiology, Izmir, Turkey
}

\section{ABSTRACT}

AIM: To evaluate iatrogenic vascular injuries in the craniocervical region and their endovascular management.

MATERIAL and METHODS: Twenty-one patients (9 women, 12 men) with a mean age of 53.6 years (range 16-87 years), who underwent endovascular embolization for iatrogenic vascular injury in the craniocervical region between December 2000 and October 2015, were included in this retrospective study. Types of iatrogenic injuries, etiologies that caused these injuries and details of endovascular managements were reported.

RESULTS: The etiologies of the vascular injuries were as follows: transsphenoidal surgery $(n=9)$, skull-base surgery $(n=2)$, cholesteatoma surgery $(n=1)$, tracheostomy $(n=2)$, central venous catheterization $(n=2)$, oropharyngeal tumor operation $(n=1)$, endovascular treatment of internal carotid artery (ICA) stenosis $(n=1)$, suprasellar epidermoid tumor operation $(n=1)$, sphenoid sinus tumor surgery $(n=1)$, and speech prosthesis device placement $(n=1)$. The types of vascular injuries diagnosed at the time of angiography were; 2 occlusions, 2 stenoses, 2 dissections, 1 carotid cavernous fistula, 8 artery rupture with extravasation, and 9 pseudoaneurysms. Endovascular management of these vascular injuries were; parent artery occlusion $(P A O)(n=15)$, aneurysm occlusion $(n=3)$, covered stent $(n=1)$ and conservative management $(n=2)$. All patients except two were successfully treated. No patient had bleeding within a 30-day period after angiography. Long-term follow-up was available in all patients without occurrence of re-bleeding. One patient died due to complications related to primary vascular injury.

CONCLUSION: Although iatrogenic vascular injuries are rare, early diagnosis and management may be lifesaving. Endovascular techniques are reliable and safe in most of the patients.

KEYWORDS: Endovascular management, latrogenic injury, Craniocervical region

\section{INTRODUCTION}

$\mathrm{I}$ atrogenic vascular injury in the craniocervical region results from various diagnostic and therapeutic procedures. The objective of this article is to provide an update on the mechanism of injury and endovascular management of this potentially devastating complication. latrogenic vascular injuries were categorized according to each diagnostic or therapeutic procedure responsible for the injury, i.e. transsphenoidal surgery (TSS), skull base surgery, tumor surgery, tracheostomy, central venous catheterization (CVC), speech prosthesis device placement procedure. The mechanisms of injuries, and procedures were discussed for each type of procedure. The type of iatrogenic vascular injury mostly depends on the type of procedure. Although iatrogenic vascular injuries in the craniocervical region are rare, they are usually fatal 
and acute surgical management is generally not possible so endovascular management of such injuries is a good option with acceptable morbidity and mortality rates. We aimed to define the role of endovascular treatment in patients with iatrogenic vascular injuries in the craniocervical region. The study focused on clinical presentations, imaging findings, management and outcomes.

\section{MATERIAL and METHODS}

A retrospective review was performed for all patients who underwent endovascular treatment for iatrogenic craniocervical vascular complications during the last fifteen-year period. A total of 21 patients, who were referred for endovascular treatment of iatrogenic vascular injury, were included in this study. In 13 patients, post-operative angiography was performed just after controlling the bleeding. The other 8 patients underwent elective angiography after a period of time. Angiographic findings were labeled as carotid occlusion, stenosis, pseudoaneurysms, carotid cavernous fistula, and contrast extravasation.

Patients' demographic information, their presenting signs and symptoms, angiographic findings, type of treatment and outcomes were gathered from patient files, angiographic images and reports.

\section{RESULTS}

Patients' information, their presenting signs and symptoms, angiographic findings, type of treatment and outcomes are summarized in Table I. There were 9 females and 12 males with a mean age of 53.6 years (range 16-87 years). A part of these case series was the subject of a previous article published by the same center (6).

The iatrogenic vascular injuries were acquired during various surgical interventions involving the craniocervical region. The most common symptom was intraoperative bleeding $(n=12)$ (Figure 1A-E).

The most common endovascular strategy for the treatment of vascular injury was parent artery occlusion (PAO) $(n=15)$ (Figures $2 A-C$ and $3 A-D$ ). Before performing $P A O$, either temporary parent artery occlusion (if possible) or extensive assessment of vascular anatomy on sectional $2 \mathrm{D}$ or $3 \mathrm{D}$ computed tomography (CT) or magnetic resonance (MR) angiographic examinations were performed to check the collateral circulation. Among 15 vascular injuries treated with PAO, 8 were located intracranially, while the remaining 7 were located extracranially. In 2 of $15 \mathrm{PAO}$, patients experienced neurological worsening due to the procedure; in the first patient (patient\# 5) we had neurological worsening in spite of having enough collateral circulation, while in the second patient (patient\# 10) we had neurological worsening due to defective Willis collateralization. The parent artery could be preserved in 4 patients whose vascular injuries were located in the intracranial circulation. The remaining 2 patients were managed conservatively.

The follow-up period varied from thirty days to ten years. None of the patients re-bled during the follow-up period. One patient died of complications related to primary pathology after permanent endovascular bleeding control and two patients had residual deficits during the follow-up period. The other patients had a good outcome.

\section{DISCUSSION}

This study reviewed iatrogenic vascular injuries in the craniocervical region and their endovascular management, and clinical outcomes. The initial results were promising with high technical and clinical success rates. During the followup period, no complications were seen. To the best of our knowledge, we report the largest series of iatrogenic vascular injuries in the craniocervical region and its endovascular management in literature.

Vascular complications due to diagnostic and therapeutic procedures are less common but result in serious consequences with high morbidity and mortality rates $(16,24)$. Planning and prevention is the best treatment for iatrogenic injuries (16). Life-threatening perioperative bleeding and stroke are the most serious complications. Early diagnosis can reduce patient morbidity and mortality rates (26).

Injuries to the carotid artery are especially more common in transsphenoidal surgery (TSS). The cavernous segment of the internal carotid artery (ICA) is located close to the bony wall of the sphenoid sinus and sella turcica where it is vulnerable to injury during pituitary surgery. Previous TSS, cavernous sinus invasion by the tumor, small sella, tortuosity of the cavernous segment of bilateral ICAs and coming into contact centrally within the sella ('kissing carotids') are predisposing factors for cavernous ICA injuries during TSS $(2,6)$. Preoperative imaging with $\mathrm{CT}$ and MR imaging may decrease complications. The occurrence of vascular injury in all cases of TSS is 1.1\% $(6,7)$. The common manifestations in vascular injury during TSS are pseudoaneurysm (PA), subarachnoid hemorrhage $(\mathrm{SAH})$ or massive epistaxis. Early diagnosis and treatment can reduce complications such as rupture of PA, SAH or extradural hemorrhage, stroke and even death. Endovascular treatment has become a good option for iatrogenic cavernosal ICA lesions recently $(9,16,18,20,29)$. latrogenic ICA lacerations after TSS include carotid cavernous fistula (CCF), PA and thrombosis $(4,16)$. Balloon or coil occlusion for CCF is the preferred management option rather than open surgery $(9,16,18,20,29)$. PAs are the most dangerous vascular complications of TSS and should be treated urgently $(2,6)$. PAO can only be performed if there is good collateral circulation. However carotid PAO has risks despite a negative occlusion test result. One study documented that 5 to $20 \%$ of patients who tolerate the balloon occlusion test will still have ischemic complications after ICA PAO $(6,18)$. All our patients with iatrogenic vascular injury after TSS except one were treated successfully with PAO. One patient with ICA stenosis was managed conservatively and one patient died because of the complications related to primary injury.

In skull-base tumor surgery, there are two risk factors that can cause ICA injury. One occurs during drilling and the other during dissection of the ICA from a tumor, such as a large 


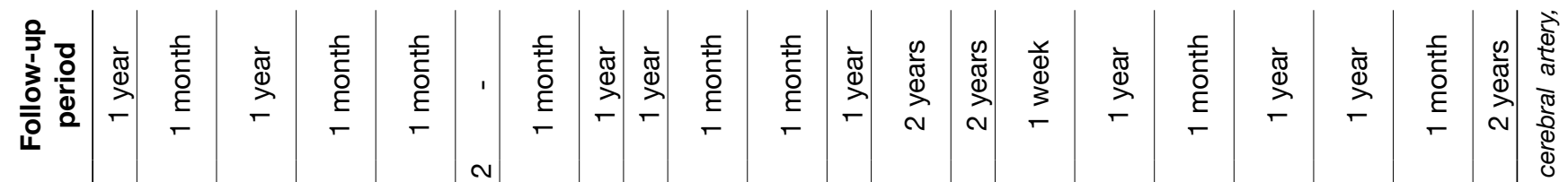

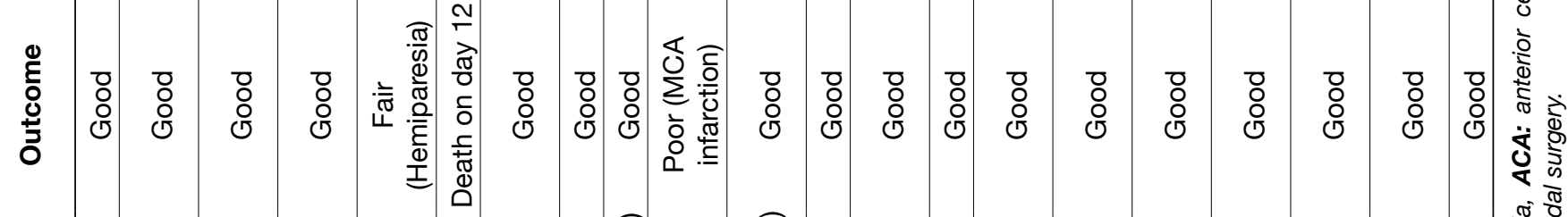

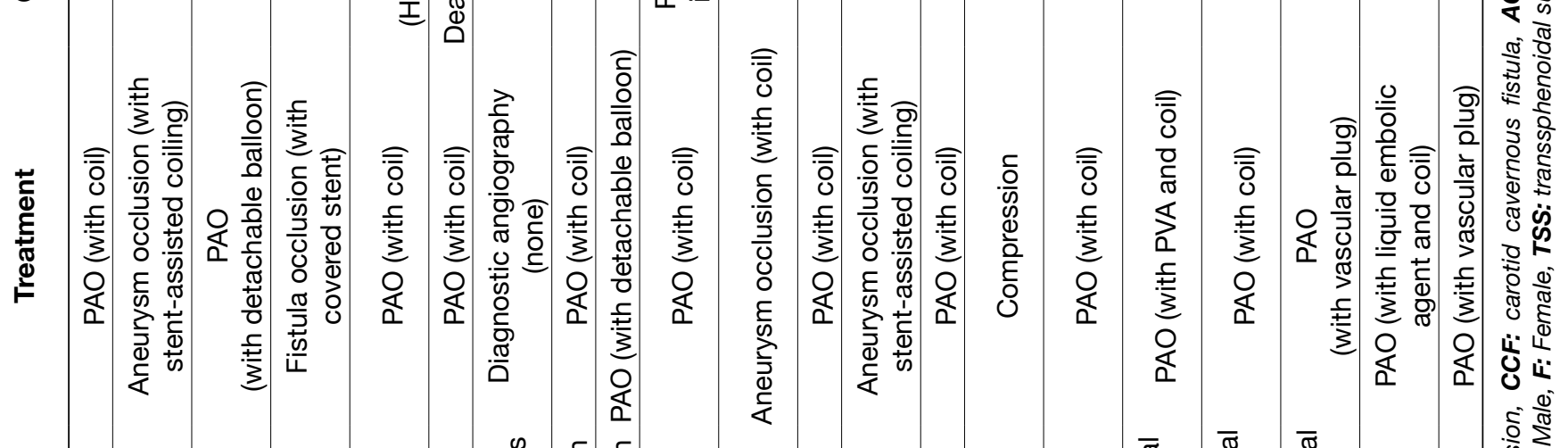

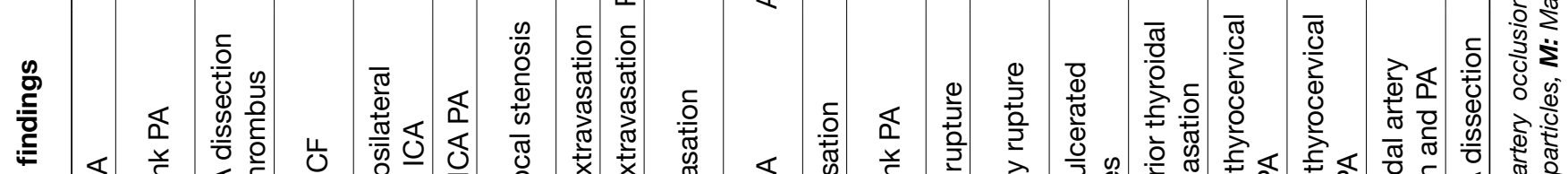

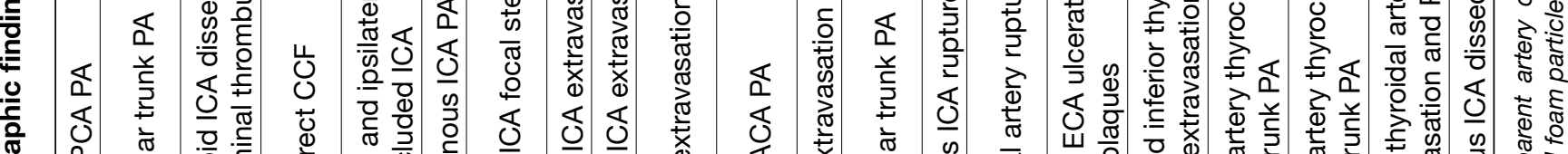

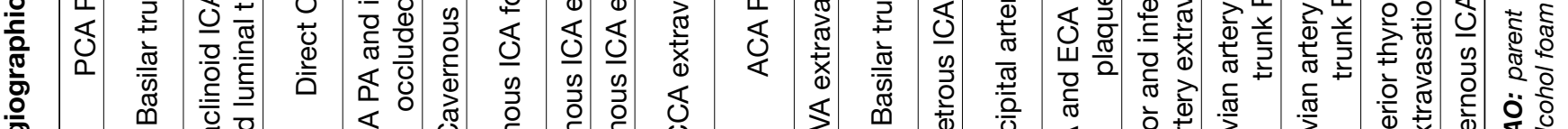

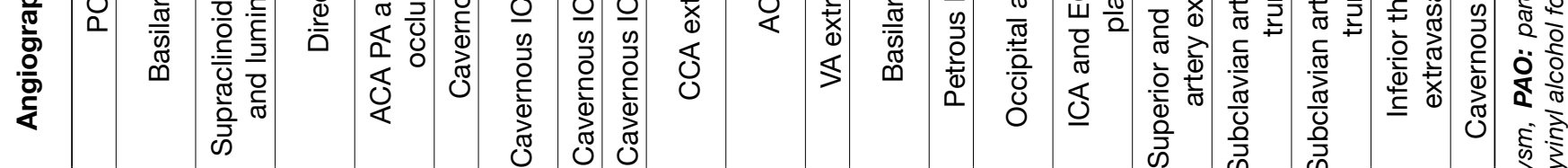

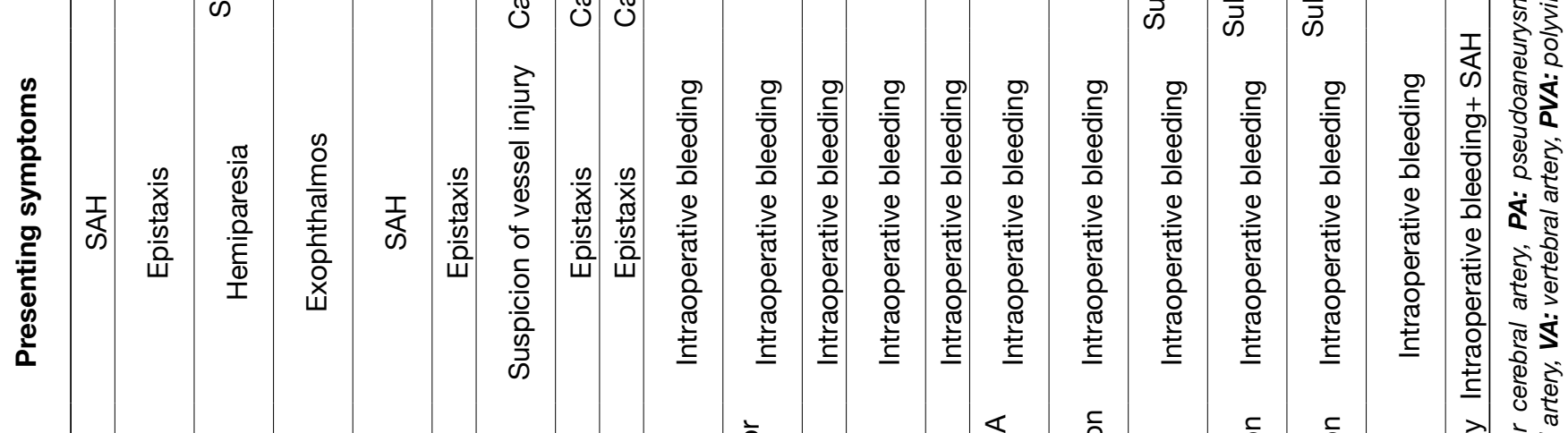

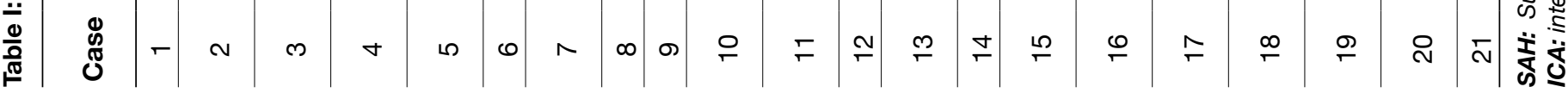


sphenoparietal or petroclival meningioma $(1,16,19,21,22)$. Papacci et al.(25) focused on co-existence of meningiomas with vascular malformations and emphasized that digital substraction angiography (DSA) remains a useful tool in giant meningiomas, not only to embolize the lesion, but also to treat tumor associated with vascular malformation and to achieve the full knowledge of vascular anatomy before surgery. In skull-base surgery, vascular injuries (such as laceration, occlusion-thrombosis, vasospasm) can occur and can be treated with endovascular techniques. Gardner et al.(12) performed a retrospective review of all endoscopic endonasal operations and found that chondroid neoplasm (chordoma, chondrosarcoma) represent a higher risk (incidence 0.3\%). In this review; the paraclival ICA segment was the most commonly injured site, and transclival and transpterygoid ICA were also affected sites. Mine et al. (23) pointed out that skull
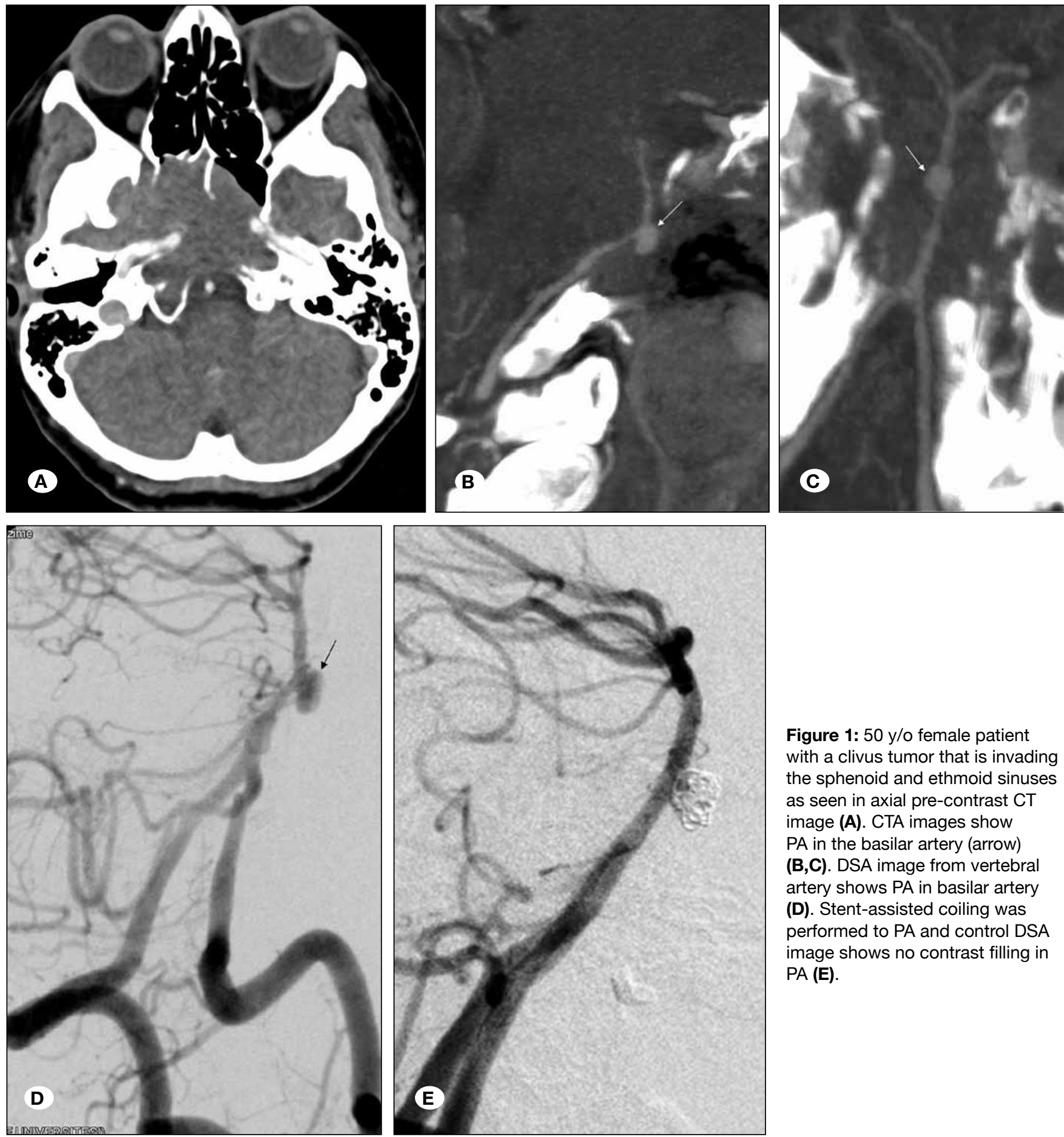

Figure 1: $50 \mathrm{y} / \mathrm{o}$ female patient with a clivus tumor that is invading the sphenoid and ethmoid sinuses as seen in axial pre-contrast CT image (A). CTA images show PA in the basilar artery (arrow) (B,C). DSA image from vertebral artery shows PA in basilar artery (D). Stent-assisted coiling was performed to PA and control DSA image shows no contrast filling in PA (E). 
base tumor surgery related iatrogenic vascular lesions may be successfully treated with endovascular techniques. Two patients with vascular injuries due to skull base surgery were treated endovascularly. One patient (patient\# 12) had vertebral artery extravasation and was treated with PAO and the other (patient\# 13) had basilar trunk PA and was treated with stent and coiling.
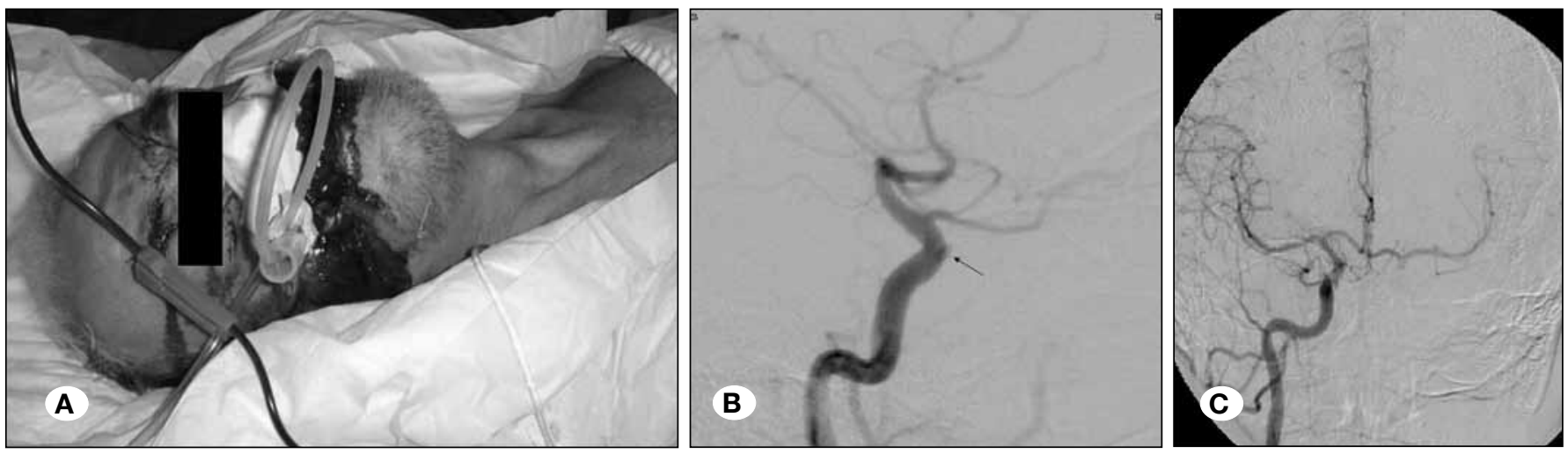

Figure 2: 69 y/o male patient who underwent transsphenoidal pituitary surgery had massive epistaxis after surgery (A). In the DSA (B) image, a small PA was detected in the cavernous segment of ICA and PAO was performed (C).
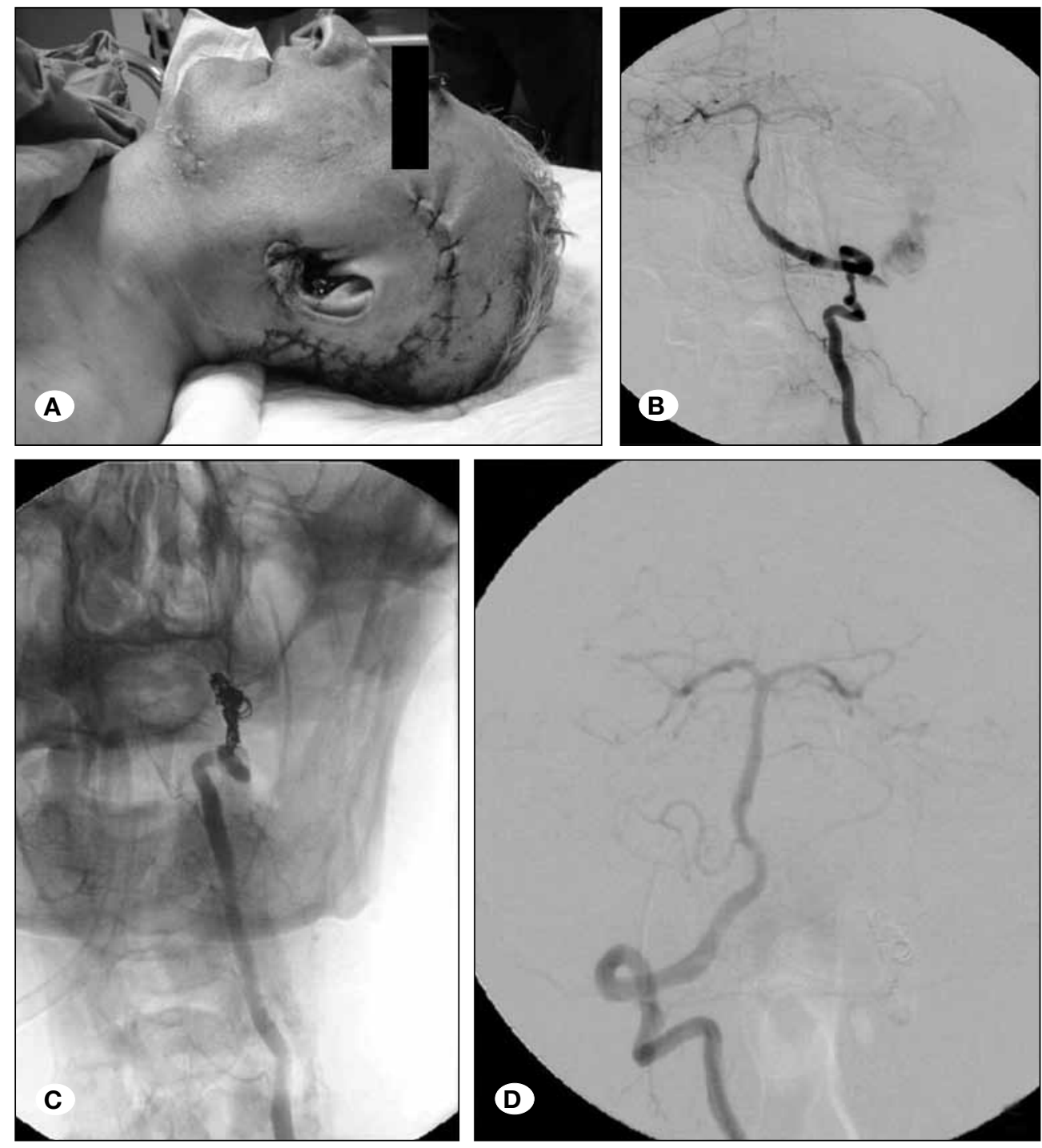

Figure 3: 52 y/o male patient with post-operative active bleeding after skull-base surgery (A). DSA from vertebral artery shows active contrast extravasation from vertebral artery (B). Control DSA shows no active bleeding after PAO with coiling (C,D). 
Complications of cerebral angiography include cerebral ischemia (thromboembolism from catheters or guide wires) and arterial injury (arterial dissection incidence of 0.07-0.3\%) $(8,16,30)$. Fifi et al. $(10)$ detected one patient $(0.03 \%)$ who had stroke with no apparent clinical deterioration and iatrogenic dissections were been seen in five arteries $(0.14 \%)$ among 3,636 diagnostic catheter cerebral angiograms. Our patient (patient\# 15) had occipital artery rupture due to catheter exchange during angioplasty treatment of ICA stenosis with stent. This patient was managed conservatively with external compression.

Tracheostomy had a complication of bleeding with a reported incidence of $4-80 \%$. Most of the vascular injuries were from the venous system (anterior jugular or facial vein), or a tracheoarterial fistula $(12,16,25)$. Our patients who had bleeding during the tracheostomy procedure had injury to the superior and inferior thyroidal arteries. Endovascular management for these injuries was embolization.

One of our patients with larynx carcinoma had bleeding while the physician was placing the speech apparatus. Common carotid artery extravasation was seen by angiography and PAO performed inevitably for the treatment in spite of insufficient collateral circulation. Unfortunately, middle cerebral artery (MCA) infarction occurred after PAO.

Central venous catheterization (CVC) placement can cause iatrogenic complications, including hematoma, hemothorax, hemorrhage, PA, AVF, and stroke. Large-bore catheters are associated with serious complications (28). The most common inadvertent arterial puncture site is the carotid artery (16), but other cervical arteries may also be involved, such as the vertebral artery (26), thyrocervical trunk (5), innominate artery (13), and even the internal mammary artery (24). In some articles, inadvertent arterial puncture with a small needle has been reported at a range of $4.2-9.3 \%(3,6,14,28)$. The most devastating complications from arterial misplacement of a large-bore catheter ( $>7 \mathrm{Fr}$ ) have an incidence of 0.1 to $1.0 \%$ (2,14-17). Rossi et al. (27) reported a female patient with iatrogenic left subclavian PA during jugular vein cannulation for hemodialysis therapy. Endovascular treatment with deployment of a covered stent into the left subclavian artery after embolization of the origin of the left internal mammary artery with a vascular plug (Amplatzer ${ }^{\mathrm{TM}}$ Vascular Plug 4) was performed. In our study, we had two patients with subclavian artery thyrocervical trunk PA due to CVC placement. Endovascular treatment with embolization of the parent artery was performed.

During tumor excision, there is also risk for vascular injuries. $\mathrm{PA}$, dissection, extravasation are the complications that can be seen (16). In our study we had three patients with such complications (ICA dissection, ICA-external carotid artery "ECA" ulceration and anterior cerebral artery "ACA" PA).

ICA injury during middle ear surgery can be seen because of the close anatomical association between the petrosal ICA and the middle ear. Approximately $1 \%$ of the population has a congenital dehiscence of the bony covering at this segment. Injury of ICA during myringotomy has been reported in 60 patients in the literature $(10,11,16)$. A persistent stapedial artery can be a cause for bleeding too. As this artery may contribute to the brain's blood supply, an angiographic evaluation has been recommended before performing occlusion. Endovascular procedures such as stenting or PAO (with coiling) are the preferred treatment.

Limitations of our study include its retrospective design and variable patient follow-up.

\section{CONCLUSION}

latrogenic vascular injuries are rare, but can have serious complications. Early diagnosis and management is crucial in such cases. Endovascular treatment of such cases is a good option with low mortality and morbidity rates.

\section{- REFERENCES}

1. Abdel-Aziz KM, Froelich SC, Dagnew E, Jean W, Breneman JC, Zuccarello M, van Loveren HR, Tew JM Jr: Large sphenoid wing meningiomas involving the cavernous sinus: Conservative surgical strategies for better functional outcomes. Neurosurgery 54: 1375-1384, 2004

2. Ahuja A, Guterman LR, Hopkins LN: Carotid cavernous fistula and false aneurysm of the cavernous carotid artery: Complications of transsphenoidal surgery. Neurosurgery 31: 774-778, 1992

3. Bell RS, Vo AH, Roberts R, Wanebo J, Armonda RA: Wartime traumatic aneurysms: Acute presentation, diagnosis, and multimodal treatment of 64 craniocervical arterial injuries. Neurosurgery 66: 66-79, 2010

4. Cappabaianca P, Briganti F, Cavallo LM, de Divitiis E: Pseudoaneurysm of the intracavernous carotid artery following endoscopic endonasal transsphenoidal surgery, treated by endovascular approach. Acta Neurochir 143:95-96, 2001

5. Chaloupka JC, Putman CM, Citardi MJ, Ross DA, Sasaki CT: Endovascular therapy for the carotid blow-out syndrome in head and neck surgical patients: Diagnostic and managerial considerations. Am J Neuroradiol 17: 843-852, 1996

6. Cinar C, Bozkaya, Parildar M, Oran I: Endovascular management of vascular injury during transsphenoidal surgery. Interv Neuroradiol 19: 102-109, 2013

7. Ciric I, Ragin A, Baumgartner C, Pierce D: Complications of transsphenoidal surgery results of a national survey, review of the literature, and personal experience. Neurosurgery 40: 225-236, 1997

8. Cloft HJ, Jensen ME, Kallmes DF, Dion JE: Arterial dissections complicating cerebral angiography and cerebrovascular interventions. Am J Neuroradiol 21: 541-545, 2000

9. Cockroft KM, Carew JF, Trost D, Fraser RA: Delayed epistaxis resulting from external carotid artery injury requiring embolization: A rare complication of transsphenoidal surgery: Case report. Neurosurgery 47: 236-239, 2000

10. Fifi JT, Meyers PM, Lavine SD, Cox V, Silverberg L, Mangla $\mathrm{S}$, Pile-Spellman J: Complications of modern diagnostic cerebral angiography in an academic medical center. J Vasc Interv Radiol 20: 442-447, 2009 
11. Freeman $B D$, Isabella $K$, Lin N, Buchman TG: A meta-analysis of prospective trials comparing percutaneus and surgical tracheostomy in critically ill patients. Chest 118:1412-1418, 2000

12. Gardner PA, Tormenti MJ, Pant H, Fernandez-Miranda JC, Snyderman $\mathrm{CH}$, Horowitz MB: Carotid artery injury during endoscopic endonasal skull base surgery: Incidence and outcomes. Neurosurgery 73: 261-269, 2013

13. Ge BH, Copelan A, Scola D, Watts MM: latrogenic percutaneous vascular injuries: clinical presentation, imaging, and management. Semin Intervent Radiol 32: 108-122, 2015

14. Halbach VV, Higashida RT, Dowd CF, Fraser KW, Smith TP, Teitelbaum GP, Wilson CB, Hieshima GB: Endovascular treatment of vertebral artery dissections and pseudoaneurysms. J Neurosurg 79:183-191, 1993

15. Hornibrook J, Rhode JC: Fatal epistaxis from an aneurysm of the intracranial internal carotid artery. Aust N Z J Surg 51: 206-208, 1981

16. Inamasu J, Guiot $\mathrm{BH}$ : latrogenic carotid artery injury in neurosurgery. Neurosurg Rev 28: 239-247, 2005

17. lob I, Scanarini M, Salar G, Ori C: Traumatic cerebral aneurysm in pediatric age. Case report. J Neurosurg Sci 27:187-190, 1983

18. Kadyrov NA, Friedman JA, Nichols DA, Cohen-Gadol AA, Link MJ, Piepgras DG: Endovascular treatment of an internal carotid artery pseudoaneurysm following transsphenoidal surgery. Case report. J Neurosurg 96: 624-627, 2002

19. Kinugasa K, Yamada T, Ohmoto T, Taguchi K: latrogenic dissecting aneurysm of the internal carotid artery. Acta Neurochir 137:226-231, 1995

20. Kocer N, Kizilkilic O, Albayram S, Adaletli I, Kantarci F, Islak C: Treatment of iatrogenic internal carotid artery laceration and carotid cavernous fistula with endovascular stent-graft placement. Am J Neuroradiol 23: 442-446, 2002

21. Kuroki K, Taguchi H, Yukawa O: Intracavernous iatrogenic aneurysm causing subarachnoid hemorrhage after removal of intracranial tumor, treated by coil embolization. No Shinkei Geka 32: 955-959, 2004
22. Lee KS: Extradural approach to the lateral sellar compartment. Yonsei Medical Journal 42: 120-127, 2001

23. Mine B, Delpierre I, Hassid S, De Witte O, Lubicz B: The role of interventional neuroradiology in the management of skull base tumours and related surgical complications. B-ENT 7: 61-66, 2011

24. Munich SA, Cress MC, Rangel-Castilla L, Krishna C, Siddiqui AH, Snyder KV: Importance of repeat angiography in the diagnosis of iatrogenic anterior cerebral artery territory pseudoaneurysm following endoscopic sinus surgery. BMJ Case Rep 2015; published online 15 May 2015. pii: bcr2015011693

25. Papacci F, Pedicelli A, Montano N: The role of preoperative angiography in the management of giant meningiomas associated to vascular malformation. Surg Neurol Int 6: 114, 2015

26. Raymond J, Hardy J, Czepko R, Roy D: Arterial injuries in transsphenoidal surgery for pituitary adenoma; The role of angiography and endovascular treatment. Am J Neuroradiol 18: 655-665, 1997

27. Rossi UG, Petrocelli F, Ferro C: Subclavian artery pseudoaneurysm complicating central venous catheterization: Endovascular treatment with Amplatzer Vascular Plug 4 and covered stent. Catheter Cardiovasc Interv 82:906-910, 2013

28. Tonnessen $\mathrm{BH}$ : latrogenic injury from vascular access and endovascular procedures. Perspect Vasc Surg Endovasc Ther 23: 128-135, 2011

29. Vanninen RL, Manninen HI, Rinne J: Intrasellar iatrogenic carotid pseudoaneurysm: Endovascular treatment with a polytetrafluoroethylene-covered stent. Cardiovasc Intervent Radiol 26: 298-301, 2003

30. Willinsky RA, Taylor SM, TerBrugge K, Farb RI, Tomlinson G, Montanera W: Neurologic complications of cerebral angiography: Prospective analysis of 2,899 procedures and review of the literature. Radiology 227: 522-528, 2003 